\title{
Examining the Links Leading to Behavioral Support for Change: An Expectancy Theory Perspective
}

\author{
Farhan Mehboob $^{1}$ (D), Noraini Othman' ${ }^{2}$ iD \\ ${ }^{1,2}$ School of Business Management, Universiti Utara Malaysia, Sintok, Malaysia.
}

\section{ABSTRACT}

Keywords:

Organizational Change,

Behavioural Support

for Change, Change-

efficacy, Change-

valence, Expectancy

Theory.
Purpose of the study: An individual's support for change is a critical factor in successfully and effectively implementing change. Therefore, identifying possible antecedents and mechanisms leading to one's behavioral support for change is necessary. The study aims to unpack this avenue of research empirically by examining the role of both person and context as factors in promoting behavioral support for change.

Methodology: Data was collected from 292 academic staff members of six public sector universities in Pakistan via cross-sectional means. A self-reported questionnaire was used to collect responses from the desired sample. SPSS 25 and AMOS were used to analyze the data for its relevance to the objectives of the study.

Main Findings: Results revealed a positive impact of change-efficacy on academic staff members' behavioral support for change. Moreover, change-valence provides an effective intervening mechanism to translate the effect of change-efficacy on both dimensions of behavioral support for change, that is, compliance and championing behavior.

Research limitations/implications: The study contributes to the existing literature on organizational change, particularly in the university setting, by examining and empirically validating the factors of both person and context as significant predictors of behavioral support for change among academic staff. However, more research is needed in other organizational and work contexts to further apply the study's implications within these diverse contexts.

Novelty/Originality of this study: The study offers useful insights for senior university officials intending to build support for change by enhancing academic staff levels of efficacy and positive expectations regarding such change and enables them to successfully execute the change-related tasks into viable actions.

\section{INTRODUCTION}

Advanced technology, competitive pressure, globalization and a changing workforce are several key external factors that prompt organizations to engage in and adapt to change, and attempt to manage it effectively (Stouten, Rousseau, \& Cremer, 2018). The nature and scope of this change are themselves quite diverse, comprising multiphase interventions and existing in various forms such as downsizing (Day, Armenakis, Feild, \& Norris, 2012), mergers (Kavanagh \& Ashkanasy, 2006), restructuring and strategic change (Wanberg \& Banas, 2000) and quality improvement initiatives (Coyle-Shapiro, 1999). This diversity in change makes it problematic to evaluate its ultimate outcomes (Stouten, Rousseau, \& Cremer, 2018). Although change-led interventions are necessary for organizations to survive and flourish notwithstanding socio-economic fluctuations (Burke, 2017), these are also sources of considerable stress to organizational members as it is they who are directly exposed to these transformations (Schreyogg \& Sydow, 2010). Pertaining to the complexity of organizational change, the latest figures also reveal staggeringly high failure rates of successfully accommodating change, up to $70 \%$ (Jarrel, 2017). Therefore, identifying ways to enable sustainable and meaningful change poses a serious challenge.

In response to contemporary ways of doing business and providing services through structural and process transformations, employee responses towards these change initiatives are becoming increasingly vital to understand, in order to sustain change and make it a more successful venture (van den Heuvel, Demerouti, \& Bakker, 2014; Oreg, Vakola, Armenakis, 2011; Oreg, Bartunek, Lee, \& Do, 2018). The prevailing consensus is that an employee's positive reaction and support is key to successful organizational change (Bakari, Hunjra, \& Niazi, 2017; Zhao, Seibert, Taylor, Lee, \& Lam, 2016). For instance, previous research concerning organizational change has demonstrated that one major cause of the massive failure rates is lack of support for change among employees; approximately two-thirds of the failures of change initiatives have occurred due to this (Jansson, 2013; Michel, By, \& Burnes, 2013).

Given the role of individual support as a key factor in effecting change successfully, identifying ways to evaluate responses related to support for change has developed as a crucial concern. To address this issue, the current study examines the potential intervening mechanisms through which change supportive behavioral responses are likely to be manifested and how this could lead organizations toward better adaptation to the change. In particular, the study aims to reveal the role of context and person

${ }^{1}$ Corresponding Author: farhan.mehboob9@gmail.com

Please cite this article as: Mehboob, F., \& Othman, N. (2020). Examining the Links Leading to Behavioral Support for Change: An Expectancy Theory Perspective. International Journal of Social Sciences and Economic Review, 2(4), 1-8. doi:10.36923/ijsser.v2i4.78 
as factors in facilitating one's behavioral support for change. In order to understand the innate complexities of organizational change and its implications, consideration of both personal and contextual factors is important when attempting to capture the essence of organizational change, and its effective implementation within its respective setting. Although past literature on organizational change has examined both personal and contextual factors as fundamental in successfully bringing about change (Oreg et al., 2011; Rafferty, Jammieson, \& Armenakis, 2013), hitherto they have rarely been explored in combination within a single study (Fugate \& Soenen, 2018).

To assist in bridging the gap in the current state of knowledge, this study addresses this limitation by focusing on the corresponding factors and their underlying relationship pattern in response to organizational change. Specifically, the study seeks to examine the intervening role of change-valence (context factor) in the relationship between the change-efficacy (personal factor) and individual behavioral support for change (support factor). The study argues that change-efficacy to behavioral support for change relationships is mediated and effectively translated when an individual's valence level is found to be high. In brief, one's change-efficacy is likely to induce positive expectations and valence among individuals regarding organizational change which may lead to subsequent change-oriented support behaviors.

\section{LITERATURE REVIEW}

\subsection{Impact of Change-efficacy on Behavioral Support for Change}

Previous research on organizational change opined that individual perceptions and beliefs towards change result in behaviors that are persistent, effortful and focused in their attempts to support and facilitate the effective implementation of the change initiatives (Haffar et al., 2019; Iqbal \& Haq, 2018; Oreg et al., 2011; Oreg et al., 2018; Rafferty et al., 2013). Taking one account of the behavioral perspective towards change, Herscovitch and Meyer (2002) distinguished these behavioral manifestations in relation to their level of activation and support towards change. This occurred through either passive or active orientation, in other words, compliance and championing behavior. According to the authors, the minimally acceptable level of support that can be carried out during the change is 'compliance' with the statutory instructions, rules and directions in view of the change under consideration. It is "demonstrating minimum support for a change by going along with the change, but doing so reluctantly" (Herscovitch \& Meyer, 2002, p. 478). Compliance "occurs when the target person carries out the requested action but is apathetic about it rather than enthusiastic, makes only a minimal or average effort, and does not show any initiative" (Falbe \& Yukl, 1992, p. 639). Championing behavior, on the other hand, involves "demonstrating extreme enthusiasm for a change by going above and beyond what is formally required to ensure the success of the change and promoting the change to others" (Herscovitch \& Meyer, 2002, p. 478). Championing "occurs when a target person agrees internally with an action or decision, is enthusiastic about it, and is likely to exercise initiative and demonstrate unusual effort and persistence in order to carry out the request successfully" (Falbe \& Yukl, 1992, p. 640). Discretionary efforts are therefore crucial as practical and conceptual means of distinguishing between employee compliance and championing behavior. Accordingly, identifying relative antecedents and their relationships with these forms of support behavior is valuable for both researchers and practitioners. The subsequent significance of behavioral support for change, combined with the paucity of empirical research examining the bilateral perspectives on support behaviors, provide a core rationale for this study.

Drawing on social cognitive theory, self-efficacy is the core determinant of whether an individual can successfully translate reality according to his or her intention ( $\mathrm{Ng} \&$ Lucianetti, 2016). Self-efficacy comprises confidence in one's own capacity to coordinate and execute the course of actions required to manage a given set of circumstances (Bandura, 1995). It represents one's perceived conviction, competence and optimistic assessment that he or she can successfully execute the action required to reach the desired end (Hughes, Galbraith, \& White, 2011). Holt et al. (2007) defined efficacy belief as the "extent to which one feels that he or she has or does not have the skills and is or is not able to execute the tasks and activities that are associated with the implementation of the prospective change" (p. 238). According to them, individuals with high efficacy belief regard themselves as more capable of performing tasks successfully once a change is made.

Consistent with the rationale highlighting the significance of self-efficacy in contributing to the employees' accomplishment of performance objectives, previous studies have also supported the role of efficacy in bringing about organizational change (see e.g. Amiot, Terry, Jimmieson, \& Callan, 2006; Jimmieson, Terry, \& Callan, 2004). Moreover, recent research has also identified the positive role of efficacy in determining change-related outcomes (Bakari et al., 2017; Haffar et al., 2019; Rafferty \& Minbashian, 2019). Studies have noted that one's self-efficacy is particularly instrumental in one's ability to accomplish job requirements in presence of adverse or demanding situations, such as those which occur during organizational change (see e.g. Bakari et al., 2017; Rafferty \& Minbashian, 2019). For instance, while examining the role of change-efficacy as a predictor to employee change supportive behaviors, Rafferty and Minbashian (2019) observed that employees with high levels of changeefficacy would likely and deliberately engage in change supportive behaviors. A study by Bakari et al. (2017) also noted changeefficacy as an antecedent to one's commitment to change. In brief, when individuals perceive that they have the capacity to accomplish their set performance objectives in response to a change initiative, this enhances their perceived extent of available opportunities to engage in supportive behaviors. This results in the manifestation of more instances of supportive behavior in relation to the corresponding organizational change. In view of the theoretical rationale and empirical evidence, the study therefore hypothesized that change-efficacy is related to both the compliance and championing dimensions of individual support toward change.

Hla: Change-efficacy is positively related to compliance behavior

Please cite this article as: Mehboob, F., \& Othman, N. (2020). Examining the Links Leading to Behavioral Support for Change: An Expectancy Theory Perspective. International Journal of Social Sciences and Economic Review, 2(4), 1-8. doi:10.36923/ijsser.v2i4.78 
H1b: Change-efficacy is positively related to championing behavior

\subsection{Mediating Role of Change-valence in the Relationship between Change-efficacy and Dimensions of Behavioral Support for Change}

There is a common belief that efficacy will improve the motivation level of employees, which has its roots in expectancy theory. According to Vroom (1964), the magnitude of an individual's motivation primarily relies on three facets, namely valence, expectancy and instrumentality. Valence refers to the value of potential rewards that are expected to be delivered as a result of achieving certain performance objectives. Expectancy refers to the probability assessment and the likelihood of success appraised by an individual that he or she can achieve the set targets. Meanwhile, instrumentality refers to the possibility that the promised reward will actually be delivered once the performance targets are achieved. In the context of this study, an examination was conducted of the conditions in which employees are attracted by the incentives afforded by change, or by the anticipation of perceived benefits they will be offered in return (valence) and which they believe they have the capacity to attain (efficacy: high expectancy).

In terms of expectancy theory, change-valance has been defined as one's belief that prospective change entails extrinsic or intrinsic values or benefits (Armenakis \& Harris, 2009). It refers to the perceived benefits of specific change that employees appraise for themselves (Holt et al., 2007). It reflects the concept that change initiative is beneficial and possesses an element of greater value for them (Armenakis \& Harris, 2009). According to Haffar et al. (2019), the extent of employees' participation in change and willingness to adapt to it is high when perceived promotional opportunities associated with the change are also high, leading ultimately to a greater degree of change implementation. In several case studies, valence has been identified as an important feature influencing employee reactions to change (see e.g. Faupel \& Sub, 2019; Haffar et al., 2019; Rafferty \& Minbashian, 2019). For instance, Zimmermann et al. (2017), while examining the impact of change in a sample of UK firms that had offshored their business across various countries, observed that the magnitude of employees' commitment to the corresponding change was higher when their level of valence was high. Likewise, Haffar et al. (2019) reported that employees with a high degree of valence were found to be more associated with the acceptance of overall quality management practices.

With regards to the role of change-valence as a mediator, expectancy theory adequately explains this mechanism, wherein the extent to which employees held high expectations of the targeted object was shaped by his or her efficacy belief. Such high expectations unleashed motivational orientation which led to greater productivity and performance (Lee, 2019). In a recent study, Faupel and Sub (2019) also noted change-valence as an effective motivational mechanism to spur change support behavior among employees. Though, self-efficacy has also been identified as a strong determinant pertaining to expectancy-related valence attributes in a variety of contexts such as organizational studies (Tannenbaum, Mathieu, Salas, \& Cannon-Bowers, 1991), education (Zimmerman, Bandura, \& Martinez-Pons, 1992), and public organizations (Lee, 2019). However, this study strives to examine the mediating role of change-valence and its mechanism to effectively transform one's positive appraisals into support behaviors, within the university context in particular. We argue that confidence in one owns ability to implement change will likely to enhance the positive expectations that they can implement change and that change will benefit them in the long run once being executed. Thus, we hypothesize that change-valence positively mediates the relationship between changeefficacy and dimensions of behavioral support for change.

\section{H2a: Change-valance mediates the positive relationship between change-efficacy and compliance behavior}

H2b: Change-valance mediates the positive relationship between change-efficacy and championing behavior

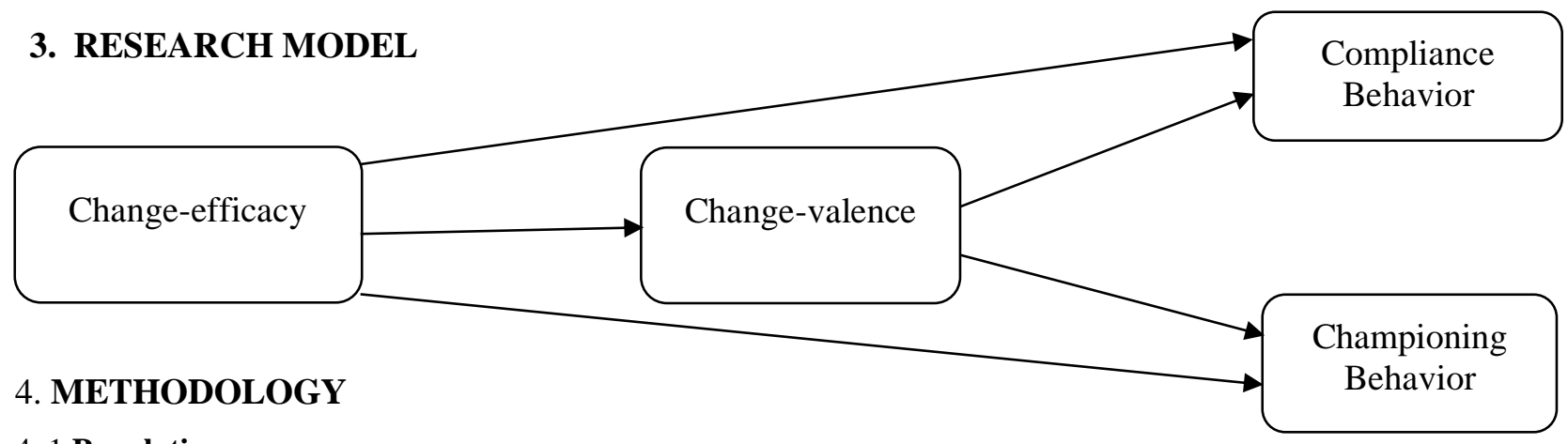

\section{4..1 Population}

Academic staff members of six public sector universities located in two provinces (Punjab and Sindh) of Pakistan were the population of this study from whom the data was drawn. The universities have been experiencing the quality enhancement initiatives undertaken by the Higher Education Commission of Pakistan, such as implementation of performance appraisal, tenure track status (TTS), research and promotion policies. Using Krejcie and Morgan (1970) sample determination criteria, the study distributed 545 questionnaires to targeted participants and retrieved 308 questionnaires in response, thus accounting for a $57 \%$ response rate. After screening the data for multivariate outliers, 292 responses were found usable for data analysis. Within these usable responses, male participants constituted $73 \%$ of the sample. Participants aged 36 to 45 years represented the age 
group with the highest proportion of respondents, $31 \%$. Meanwhile, $24 \%$ of the participants possessed experience ranging from 16 to 20 years of service. Around $55 \%$ of them were lecturers, while $49 \%$ possessed a master's degree.

\subsection{Measures}

Behavioral support for change was measured using a 9-item scale comprising compliance ( 3 items) and championing behavior (6 items) developed by (Herscovitch \& Meyer, 2002). The scale was revised with certain amendments: 'organization' was replaced with 'university', while 'change' was labeled a quality enhancement initiative by a university. Sample items included: "I speak positively about the quality enhancement initiative introduced by the university to colleagues." Cronbach's alpha was found to be 0.49 and 0.90 respectively. The reliability value fell below the threshold value of 0.70 ; nevertheless, previous studies examining BSC reported acceptable reliability statistics for the compliance subscale. For example, Fugate and Soenen (2018) and Bakari et al. (2017) found a reliability coefficient of 0.91 and 0.96 respectively for the compliance subscale. Meanwhile, change-efficacy was measured using a 6-item scale developed by Holt, Armenakis, Feild and Harris (2007). Sample items included: "I have the skills that are needed to make this change work." The Cronbach's alpha value of change-efficacy was reported as 0.82 . Change-valance was measured using a three-item scale conceptualized by (Holt et al., 2007). Sample items included: "My future in this job will be limited because of this quality enhancement initiative introduced by the University." (Reverse Item). The reliability coefficient of change-valence was found to be 0.66. However, Rafferty and Minbashian (2019), reported its value as well above the acceptable level, at 0.96. All four constructs were measured on a five-point Likert scale ranging from $1=$ Strongly disagree to $5=$ Strongly agree.

\section{RESULTS / ANALYSIS}

A confirmatory factor analysis was performed using AMOS 23 to assess the goodness of fit of the measurement model. For this purpose, three model fit indices were used (i.e. Comparative fit index, CFI: Tucker-Lewis index, TLI: \& Root Mean Square Error of Approximation, RMSEA) to evaluate the validity of the proposed model. According to Hair, Black, Babin \& Anderson (2019), fit values greater than or equal to 0.95 for CFI and TLI, while RMSEA value of less than or equal to 0.05 , show a good fit model. On this basis, four alternative models were compared and tested (as determined by Bentler \& Bonett, 1980), whereby the hypothesized model showed a better fit relative to the competing models (CFI $=0.98$; TLI $=0.97 ;$ RMSEA $=0.02 ; \mathrm{p}<$ 0.000 ), which indicates that the study's research model was better aligned with the retrieved dataset (see Table 1). Moreover, the factor analysis results also showed the adequate validity of the working constructs as each item was loaded on its own measure (See Appendix for details).

TABLE 1

Model Fit Indices

\begin{tabular}{|c|c|c|c|}
\hline Model Summary & CFI & TLI & RMSEA \\
\hline 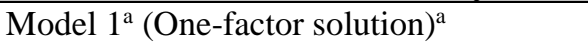 & 0.64 & 0.59 & 0.13 \\
\hline Model $2^{\mathrm{b}}$ (Two-factor solution) $^{\mathrm{b}}$ & 0.74 & 0.71 & 0.11 \\
\hline 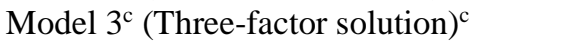 & 0.85 & 0.83 & 0.08 \\
\hline Model $4^{\mathrm{d}}$ Original (Four-factor solution) ${ }^{\mathrm{d}}$ & 0.98 & 0.97 & 0.02 \\
\hline
\end{tabular}

a. One-factor solution = all items loaded on Compliance Behavior

b. Two-factor solution= items loaded on Compliance Behavior and Change-efficacy

c. Three-factor solution = items loaded on Compliance Behavior, Change-Efficacy and Change-valence

d. Four-factor solution = items loaded on Compliance Behavior, Change-Efficacy, Change-valence and Championing Behavior

Table 2 illustrates the summary of the descriptive statistics, including zero-order correlation and reliability analysis of the working constructs. The mean values of all factors were found to be above their relative midpoint, ranging from $\mathrm{M}=3.29$ to $\mathrm{M}$ $=3.60$, thus indicating that the academic staff generally concurred with the statements presented during the data collection. Moreover, the reliability analysis assessed using Cronbach's alpha values also fell above the threshold level of 0.70 (as suggested by Nunnally (1978), ranging from 0.78 to 0.83 , thereby showing the scales used to measure the constructs were reliable. In addition, all inter-construct correlations were found to be significant, which suggested support for the hypotheses. Specifically, the relationship between change-efficacy and compliance behavior was revealed to be stronger $(r=0.45)$ than the others.

\section{TABLE 2}

Descriptive and Reliability Statistics

\begin{tabular}{lllllll}
\hline & & Mean & SD & $\mathbf{1}$ & $\mathbf{2}$ & $\mathbf{3}$ \\
\hline 1 & Change-efficacy & 3.49 & 0.74 & $(0.78)$ & & \\
\hline 2 & Change-valence & 3.29 & 0.99 & $0.33 *(0.80)$ & & $0.36 *(0.82)$ \\
\hline 3 & Compliance Behavior & 3.60 & 1.02 & $0.45 *$ & $0.32 *$ & $0.37 *(0.83)$ \\
\hline 4 & Championing Behavior & 3.39 & 0.80 & $0.40 *$ & 0.32 \\
\hline
\end{tabular}

$* \mathrm{P}<0.05$

Values in parentheses are Cronbach's alpha for reliability assessment 
Structural regression analysis (SRA) was used to test hypotheses H1a, H1b, H2a and H2b. Hypotheses H1a and H1b concern the positive effect of change-efficacy on dimensions of behavioral support for change such as compliance and championing behavior. Results indicated that change-efficacy has a significant impact on both compliance (COMP <--- CEF: $\beta=0.513 ; S E$ $=0.074 ; p<.01$ ) as well as championing behavior (CHAMP <--- CEF: $\beta=0.364 ; S E=0.059 ; p<.01$ ), as shown in Table 3 . Hence the results provided support for the corresponding hypothetical associations.

TABLE 3

Structural Regression Analysis Results for Direct Paths

\begin{tabular}{lllrrrr}
\hline & & & Estimate & S.E. & C.R. & P \\
\hline CVL & $<---$ & CEF & .442 & .074 & 6.005 & $* * *$ \\
\hline COMP & $<---$ & CEF & .513 & .074 & 6.972 & $* * *$ \\
\hline CHAMP & $<---$ & CEF & .364 & .059 & 6.150 & $* * *$ \\
\hline COMP & $<---$ & CVL & .244 & .055 & 4.420 & $* * *$ \\
\hline CHAMP & $<---$ & CVL & .161 & .044 & 3.629 & $* * *$ \\
\hline
\end{tabular}

*** $\mathrm{p}<.01$

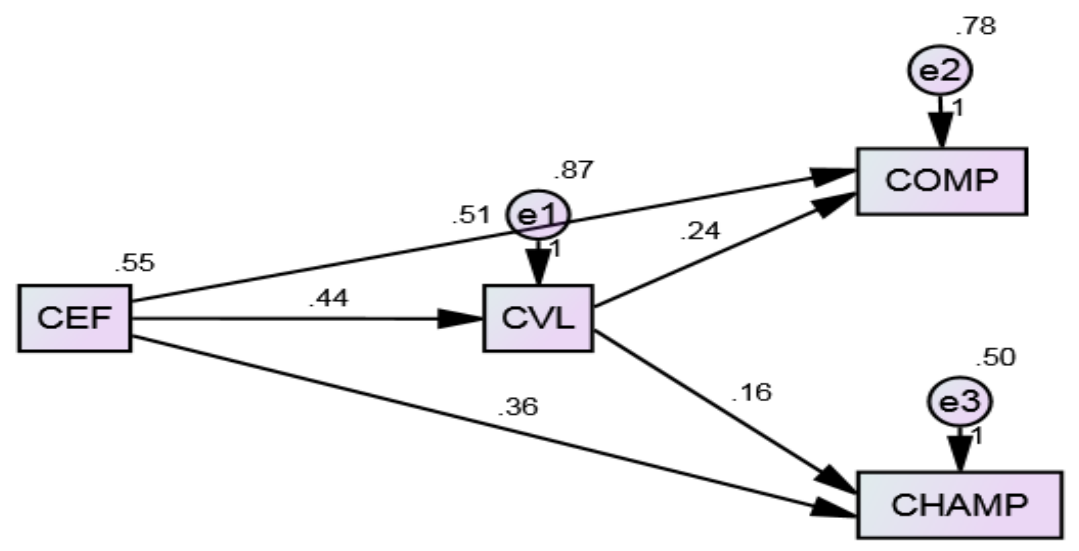

Figure 1: Path Model

Moreover, $\mathrm{H} 2 \mathrm{a}$ and $\mathrm{H} 2 \mathrm{~b}$ were designed to examine the mediating role of change-valence in translating the impact of changeefficacy to the dimensions of behavioral support for change. As predicted, results showed that the impact of change-efficacy on compliance (COMP <--- CVL <--- CEF: $\beta=0.11 ; S E=0.03 ; L L C I=0.05 ; U L C I=0.18)$ and championing behavior $(\mathrm{CHAMP}$ $<--$ CVL <--- CEF: $\beta=0.07 ; S E=0.02 ; L L C I=0.03 ; U L C I=0.12$ ) has been indirectly influenced owing to the presence of change-valence. This provides support for both hypotheses (see Table 4).

Table 4:

Mediation Analysis Results

\begin{tabular}{|c|c|c|c|c|}
\hline & \multicolumn{4}{|c|}{ Compliance } \\
\hline & \multirow[b]{2}{*}{ Estimates } & \multirow[b]{2}{*}{ SE } & \multicolumn{2}{|c|}{ BC $95 \% \mathrm{CI}$} \\
\hline & & & Lower & Upper \\
\hline Total effect of CEF on COMP & 0.62 & 0.07 & 0.48 & 0.76 \\
\hline Direct Effect of CEF on COMP & 0.51 & 0.06 & 0.37 & 0.66 \\
\hline \multirow[t]{2}{*}{ Indirect Effect of CEF on COMP via CVL } & 0.11 & 0.03 & 0.05 & 0.18 \\
\hline & \multicolumn{4}{|c|}{ Championing } \\
\hline Total effect of CEF on CHAMP & 0.44 & 0.07 & 0.32 & 0.55 \\
\hline Direct Effect of CEF on CHAMP & 0.36 & 0.06 & 0.17 & 0.40 \\
\hline Indirect Effect of CEF on CHAMP via CVL & 0.07 & 0.02 & 0.03 & 0.12 \\
\hline
\end{tabular}

Note. $\mathrm{BC}=$ Bias-corrected (5,000 bootstrapping samples); $C I=$ confidence interval

\section{DISCUSSION}

The key objective of this study was to examine change-efficacy to bring about individual behavioral support for change during times of organizational change. It also aimed to identify the potential mechanism through which this association effectively transformed into behavioral support for change. The proposed framework was established and applied using expectancy theory to explain the phenomenon under observation. The findings provided support for hypotheses $\mathrm{H} 1 \mathrm{a}$ and $\mathrm{H} 1 \mathrm{~b}$, associated with a direct link between change-efficacy and behavioral support for change. The results paralleled those of previous studies, in that change-efficacy was found to be positively related to the change-oriented outcomes for an individual (see Bakari et al., 2017; Haffar et al., 2019; Rafferty \& Minbashian, 2019). 
Furthermore, the mediation results also confirmed the role of change-valence as a potential mechanism to facilitate change supportive behaviors at both passive (compliance) and active (championing) levels. Thus, the findings support previous research that suggested change-valence has been demonstrated as a potential mediator in stimulating positive work behaviors (Lee, 2019; Faupel \& Sub, 2019). Moreover, the findings were also found to align with studies identifying change-valence as an important attribute in determining change-related support outcomes (see e.g. Haffar et al., 2019; Rafferty \& Minbashian, 2019; Zimermann et al., 2017). Results were also found to be consistent with the assumptions of expectancy theory, which suggests that when individuals perceive that a stipulated target is beneficial, they are capable of achieving it, with the likelihood of this success being high. It is more likely that such circumstances would unleash the motivational stimulation of individuals to incorporate or accept the goals under consideration. Hence this study effectively synchronized the notion under investigation empirically and validated its underpinning to the context of the research setting.

In brief, the present study addresses the scarcity of literature on organizational change by focusing on behavioral support for change and by identifying change-valence as an explanatory underlying variable. In doing so, the study helps to clarify how one's perceived support for management influences individuals during periods of change. The consideration of valence as a mediator in the present study expands current knowledge about the implications of any attractive consequences of change, should individuals find such change positive. It has been suggested in previous literature that valence can be a more proximal antecedent of an individual's reactions to change than other antecedents (Oreg et al., 2011), an idea that is empirically supported in the present study. In line with previous research, the present study found that the perception of positive outcomes of change is one of the most important factors in motivating individuals, in particular academic staff, to support change.

\section{CONCLUSION}

The study conclusively confirms the role of change-efficacy as a personal factor in inducing change supportive behaviors. It also provides support for change-valence as a contextual factor in leading processes of change. The study therefore reinforces the assumptions that both contextual and personal factors are empirically valid features to incorporate in the development of effective support for change mechanisms, as suggested by scholars (see e.g. Oreg et al., 2011; Rafferty et al., 2013; Fugate \& Soenen, 2018). Moreover, the findings also revealed that academic staff were more involved in compliance-related behavior, which is categorized as a passive mode of support behavior, than championing behavior, which has been termed an active form of behavior (Kim et al., 2011). The hypothetical associations were found to be even stronger in relation to compliance behavior than championing behavior. This suggests that the academic staff are more prone to comply with a corresponding change initiative at the minimum acceptable level than to advocate it as champions. In summary, the study provides both a theoretical and an empirical rationale for the underlying relationships of organizational change, and the process connected to the development of support for change among academic staff. The study has thereby contributed to the extant literature on change management by testing an empirically valid framework to effectively promote support for change among individuals, particularly among academic staff members of public universities in Pakistan.

\section{LIMITATION AND FUTURE RECOMMENDATIONS}

Despite the empirical contributions of the study, the findings should be acknowledged as having certain limitations. First, they are based on a cross-sectional research design and single-source data, which somewhat restricts the claim to the causal relationship reported in this study. The framework was developed with an extant literature review anchored to theoretical underpinning and results also provided support for and confirmation of the propositions. However, more research is needed, particularly in utilizing longitudinal or dyadic designs to validate the study findings. Second, the findings of the study are directly relevant only to the academic staff of public sector universities; therefore, further research is suggested across cultures, sectors and functional areas to confirm the generalizability of the research model.

\section{REFERENCE}

Amiot, C. E., Terry, D. J., Jimmieson, N. L., \& Callan, V. J. (2006). A longitudinal investigation of coping processes during a merger: Implications for job satisfaction and organizational identification. Journal of Management, 32(4), 552-574.

Armenakis, A. A., \& Harris, S. G. (2009). Reflections: Our journey in organizational change research and practice. Journal of change management, $9(2), 127-142$.

Bakari, H., Hunjra, A. I., \& Niazi, G. S. K. (2017). How does authentic leadership influence planned organizational change? The role of employees' perceptions: Integration of theory of planned behavior and Lewin's three step model. Journal of Change Management, 17(2), 155-187.

Bandura, A. (Ed.). (1995). Self-efficacy in changing societies. Cambridge university press.

Bentler, P. M., \& Bonett, D. G. (1980). Significance tests and goodness of fit in the analysis of covariance structures. Psychological bulletin, 88(3), 588-606.

Burke, W. W. (2017). Organization change: Theory and practice. Sage publications.

Coyle-Shapiro, J. A. M. (1999). Employee participation and assessment of an organizational change intervention: A three-wave study of total quality management. The Journal of Applied Behavioral Science, 35(4), 439-456.

Day, K. M., Armenakis, A. A., Feild, H. S., \& Norris, D. R. (2012). Other organizations are doing it, why shouldn't we? A look at downsizing and organizational identity through an institutional theory lens. Journal of Change Management, 12(2), $165-188$.

Falbe, C. M., \& Yukl, G. (1992). Consequences for managers of using single influence tactics and combinations of tactics. Academy of Management journal, 35(3), 638-652. 
Faupel, S., \& Süß, S. (2019). The effect of transformational leadership on employees during organizational change-an empirical analysis. Journal of Change Management, 19(3), 145-166.

Fugate, M., \& Soenen, G. (2018). Predictors and processes related to employees' change-related compliance and championing. Personnel Psychology, 71(1), 109-132.

Haffar, M., Al-Karaghouli, W., Irani, Z., Djebarni, R., \& Gbadamosi, G. (2019). The influence of individual readiness for change dimensions on quality management implementation in Algerian manufacturing organisations. International Journal of Production Economics, 207, 247-260.

Hair, J. B., Black, W., Babin, B., \& Anderson, B. R., (2019). Multivariate data analysis.

Herscovitch, L., \& Meyer, J. P. (2002). Commitment to organizational change: Extension of a three-component model. Journal of applied psychology, 87(3), 474-487.

Holt, D. T., Armenakis, A. A., Feild, H. S., \& Harris, S. G. (2007). Readiness for organizational change: The systematic development of a scale. The Journal of applied behavioral science, 43(2), 232-255.

Hughes, A., Galbraith, D., \& White, D. (2011). Perceived competence: A common core for self-efficacy and self-concept?. Journal of personality assessment, 93(3), 278-289.

Iqbal, A., \& Asrar-ul-Haq, M. (2018). Establishing relationship between TQM practices and employee performance: The mediating role of change readiness. International Journal of Production Economics, 203, 62-68.

Jansson, N. (2013). Organizational change as practice: A critical analysis. Journal of organizational change management, 26(6), $1003-1019$.

Jarrel, T. (2017). Success factors for implementing change at scale. New York: McKinsey \& Co Presentation, Behavioral Science \& Policy Association.

Kavanagh, M. H., \& Ashkanasy, N. M. (2006). The impact of leadership and change management strategy on organizational culture and individual acceptance of change during a merger. British journal of management, 17(S1), S81-S103.

Kim, T. G., Hornung, S., \& Rousseau, D. M. (2011). Change-supportive employee behavior: Antecedents and the moderating role of time. Journal of Management, 37(6), 1664-1693.

Krejcie, R. V., \& Morgan, D. W. (1970). Determining sample size for research activities. Educational and psychological measurement, 30(3), 607-610.

Lee, H. W. (2019). Moderators of the motivational effects of performance management: A comprehensive exploration based on expectancy theory. Public Personnel Management, 48(1), 27-55.

Michel, A., Todnem, R., \& Burnes, B. (2013). The limitations of dispositional resistance in relation to organizational change. Management Decision, 51(4), 761-780.

Ng, T. W., \& Lucianetti, L. (2016). Within-individual increases in innovative behavior and creative, persuasion, and change self-efficacy over time: A social-cognitive theory perspective. Journal of Applied Psychology, 101(1), 14-34.

Nunnally, J. C. (1978). Psychometric Theory: $2 d$ Ed. McGraw-Hill.

Oreg, S., Vakola, M., \& Armenakis, A. (2011). Change recipients' reactions to organizational change: A 60-year review of quantitative studies. The Journal of applied behavioral science, 47(4), 461-524.

Oreg, S., Bartunek, J. M., Lee, G., \& Do, B. (2018). An affect-based model of recipients' responses to organizational change events. Academy of Management Review, 43(1), 65-86.

Rafferty, A. E., Jimmieson, N. L., \& Armenakis, A. A. (2013). Change readiness: A multilevel review. Journal of management, 39(1), 110-135.

Rafferty, A. E., \& Minbashian, A. (2019). Cognitive beliefs and positive emotions about change: Relationships with employee change readiness and change-supportive behaviors. Human Relations, 72(10), 1623-1650.

Schreyögg, G., \& Sydow, J. (2010). Crossroads - organizing for fluidity? Dilemmas of new organizational forms. Organization science, 21(6), 1251-1262.

Stouten, J., Rousseau, D. M., \& De Cremer, D. (2018). Successful organizational change: Integrating the management practice and scholarly literatures. Academy of Management Annals, 12(2), 752-788.

Tannenbaum, S. I., Mathieu, J. E., Salas, E., \& Cannon-Bowers, J. A. (1991). Meeting trainees' expectations: The influence of training fulfillment on the development of commitment, self-efficacy, and motivation. Journal of applied psychology, 76(6), 759.

van den Heuvel, M., Demerouti, E., \& Bakker, A. B. (2014). How psychological resources facilitate adaptation to organizational change. European Journal of Work and Organizational Psychology, 23(6), 847-858.

Vroom, V. (1964). Expectancy theory. Work and motivation.

Wanberg, C. R., \& Banas, J. T. (2000). Predictors and outcomes of openness to changes in a reorganizing workplace. Journal of applied psychology, 85(1), 132.

Zhao, H. H., Taylor, M. S., Lee, C., \& Lam, W. (2015). Not Even The Past: The Joint Influence of Former Leader and New Leader in Organizational Change. Academy of Management Proceedings, 2015(1), 11364. doi:10.5465/ambpp.2015.11364abstract

Zimmerman, B. J., Bandura, A., \& Martinez-Pons, M. (1992). Self-motivation for academic attainment: The role of self-efficacy beliefs and personal goal setting. American educational research journal, 29(3), 663-676.

Zimmermann, A., Lioliou, E., \& Oliveira, J. S. (2017). Managerial work characteristics and organizational commitment after offshoring. The moderating effect of perceived organizational valence Academy of Management Proceedings. doi.org/10.5465/AMBPP.2017.11561abstract) 11561.

\section{APPENDIX}

Please cite this article as: Mehboob, F., \& Othman, N. (2020). Examining the Links Leading to Behavioral Support for Change: An Expectancy Theory Perspective. International Journal of Social Sciences and Economic Review, 2(4), 1-8. doi:10.36923/ijsser.v2i4.78 
Factor Analysis

\begin{tabular}{llr}
\hline & KMO and Bartlett's Test & .882 \\
\hline Kaiser-Meyer-Olkin Measure of Sampling Adequacy. & & 1917.053 \\
\hline Bartlett's Test of Sphericity & Approx. Chi-Square & 153 \\
\cline { 2 - 3 } & df & .000 \\
\cline { 2 - 3 } & Sig. & \\
\hline
\end{tabular}

Rotated Component Matrix ${ }^{\mathrm{a}}$

\begin{tabular}{|c|c|c|c|c|}
\hline & & Comp & & \\
\hline & 1 & 2 & 3 & 4 \\
\hline CHAMP_1 & .750 & & & \\
\hline CHAMP_3 & .737 & & & \\
\hline CHAMP_4 & .726 & & & \\
\hline CHAMP_5 & .717 & & & \\
\hline CHAMP_6 & .669 & & & \\
\hline CHAMP_2 & .662 & & & \\
\hline CEF_1 & & .771 & & \\
\hline CEF_4 & & .710 & & \\
\hline CEF_5 & & .704 & & \\
\hline CEF_6 & & .677 & & \\
\hline CEF_2 & & .628 & & \\
\hline CEF_3 & & .612 & & \\
\hline COMP_3 & & & .841 & \\
\hline COMP_1 & & & .801 & \\
\hline COMP_2 & & & .775 & \\
\hline CVL_2 & & & & .831 \\
\hline CVL_1 & & & & .812 \\
\hline CVL_3 & & & & .796 \\
\hline
\end{tabular}

Extraction Method: Principal Component Analysis.

Rotation Method: Varimax with Kaiser Normalization.

\section{Author's Biodata:}

Farhan Mehboob: Farhan Mehboob is a PhD candidate at Universiti Utara Malaysia (UUM), Sintok, Malaysia. He holds a MS degree in Management from Sukkur IBA University, Sukkur, Pakistan. He has over 7 years of professional experience in academia. Besides, Mr. Mehboob has also published several research articles and attended numerous international conferences as well. His research interests include organizational change management and development, positive psychology and behavior, learning and leadership development.

Noraini Othman: Dr. Noraini Othman is an Associate Professor at School of Business Management, Universiti Utara Malaysia. She received her doctoral degree in Organizational Behavior and Development (OB) from Universiti Sains Malaysia (USM). She teaches various courses in OB and Management discipline of the undergraduate and postgraduate levels and supervise post graduate thesis. Her research interests include job performance, engagement, change management, leaderships, and emotion management. 